\title{
The Effect of Curing and Extraction Time against Yield and Quality of Type B Gelatin from Goat Bone
}

\author{
Asrul Bahar \\ Department of Family Education \\ Welfare \\ Universitas Negeri Surabaya \\ Surabaya, Indonesia \\ asrulbahar@unesa.ac.id
}

\author{
Rusijono \\ Department of Education Technology \\ Universitas Negeri Surabaya \\ Surabaya, Indonesia \\ rusijono@unesa.ac.id
}

\author{
Nita Kusumawati* \\ Department of Chemistry \\ Universitas Negeri Surabaya \\ Surabaya, Indonesia \\ nitakusumawati@unesa.ac.id
}

\begin{abstract}
In this study evaluated the effect of preparation conditions (curing) and extraction time on the yield and quality (water and ash content, gel, and colour) of type $B$ gelatin from goat bone. In general, the yield of goat's gelatin (GBG) increases with increasing curing (10-50 days) and extraction time (4-5 hours). Under the same conditions, a decrease in water content, gel strength and brightness were detected on GBG. Specifically, lower ash content was produced from 50 days curing and 5 hours extraction compared to other conditions. In line with this, lower water content, gel strength and brightness were also observed in this condition. However, by referring to the GMIA, the highest quality GBG is obtained from the manufacturing process using a 30-day curing time and 5-hour extraction time.
\end{abstract}

Keywords-Gelatin, halal, goat, bone, curing, extraction

\section{INTRODUCTION}

Gelatin is a water-soluble protein that is produced from the partial hydrolysis of collagen making up the bone, skin and connective tissue of animals [1]. Collagen is the basic material that composes all-white fibrous connective tissue in an animal's body, which has been degraded to a second structure with several hydrolysis levels of the polypeptide backbone, either by partial hydrolysis of acids or alkaline or by thermal degradation of enzymes. This hydrolysis level divides commercial gelatin into two types, namely type A and B. Type A is generally obtained from porcine skin through acid curing before extraction, which has no significant effect on glutamine and asparagine amide groups which produce higher isoelectric points, ie in the range 7-9 [2]. Type B is generally produced from the extraction of ossein and pieces of bovine skin that have undergone an alkaline curing procedure, which triggers the hydrolysis of asparagine to aspartate and glutamine to glutamate. The type $\mathrm{B}$ isoelectric point of gelatin is in the range 4.5-6.0 [3].

Gelatin is one of the most desirable raw materials, especially in the food industry with wide application and getting food security recognition from the US Food and Drug Administration. In the food industry, gelatin is widely used as a gel binding, thickener, foam maker, stabilizer, and water binder agent. Furthermore, gelatin is relatively free of cholesterol, fat, and purine. Its dominant role in making gelatin very difficult to replace. A large amount of material is needed to produce a gelatin multifunction. The structure of the gelatin polypeptide allows interaction with many ionic and nonionic surfactants through a hydrophobic or ionic mechanism. Both of these mechanisms produce various gelatin-surfactants complex. Not only that, but gelatin has also been used widely as one of the main materials in formulations in the photography, pharmaceutical and cosmetic industries. In the pharmaceutical industry, the use of gelatin includes making hard and soft capsules and wound care [3].

Gelatin can be produced from various sources, although the physical properties of gelatin produced by each source can be very different. Porcine skin $(46 \%)$, bovine skin (29.4\%), porcine and bovine bones (23.1\%) [4] as well as fish skin and bones $(<1.5 \%)$ became the main sources of gelatin production [5]. In general, mammalian gelatin has a higher melting and gelling point than fish gelatin. This gelatin also has a higher gel strength, which is predicted to be directly related to the higher content of hydroxyproline it has [6]. However, the making of gelatin from the bovine skin and bones is getting a lot of attention, especially about the issue of bovine spongiform encephalopathy (BSE) [7]. Furthermore, it is important to look for alternative sources for the production of bovine gelatin mainly because its use gets religious sentiment throughout the world [8].

Goats are a type of mammal that is relatively free of religious sentiments and has experienced rapid growth in its population in Indonesia. In the range of 2009-2016, the goat population in Indonesia experienced growth from only amounting to $15,815,317$ to $19,608,181$. Based on BPS 2017, Central and East Java are two provinces with the largest goat population in Indonesia, with populations of 4,100,000 and $3,300,000$ each [9]. This value provides an overview of the amount of goat bone and skin waste produced along with the increase in the quantity of goat slaughter on Java island. This condition provides a great economic opportunity for the production of mammal gelatin in Java, considering that the utilization of bone and goatskin waste has not been optimal. This is in line with that published by [10]. Thus, the use of goat bones as a source of mammalian gelatin production is very promising economically. This study aimed to evaluate the effect of preparation and extraction conditions on the yield and Physico-chemical properties of type-B gelatin from goat bone material. 


\section{MATERIAL AND METHODS}

\section{A. Material}

Calcium oxide $(\mathrm{CaO})$ used for curing of the bovine bone material and hydrochloric acid $(\mathrm{HCl})$ used as a demineralization was obtained from Sigma-Aldrich (Singapore). Both are analytical grades.

\section{B. Collection and Preparation Goat Bone Material}

Goat bone samples were obtained from slaughterhouses in Pegirian-Surabaya, Indonesia. The bone samples are packaged using polyethylene bags in an isolated icebox, to avoid physiological damage and transported to the laboratory within 2 hours. After arriving in the laboratory, the bovine bone is washed using running water with a temperature of $28-30{ }^{\circ} \mathrm{C}$ then put back into a polyethylene bag and stored in a freezer with a temperature of $-20{ }^{\circ} \mathrm{C}$ (max. 2 months). Shortly before being processed, bone must be thawed first using a water bath at a temperature of 28-30 ${ }^{\circ} \mathrm{C}$ for 15 minutes.

\section{Pre-Treatment of Goat Bone Material}

The bone material that has been prepared is cut to size 5; 7 ; and $9 \mathrm{~cm}$ are then washed again with pressurized water until clean. Pieces of bone material that has been cleaned, then boiled in water at a temperature of $90^{\circ} \mathrm{C}$ for 5 hours, with a ratio of bone material: water is $1: 3(\mathrm{~kg} / \mathrm{L})$. Floating dirt and scum that appears during the boiling process is discarded. After that, the bone material is drained and dried at room temperature for 24 hours. In the next step, the bone material is roughly ground with a grinding machine up to \pm 1 $\mathrm{cm}$ in size. Furthermore, bone material was demineralized in $2 \% \mathrm{HCl}$ for 24 hours. To remove excess hydrochloric acid after the demineralization process, ossein was washed with running water, which was then followed by soaking ossein in $0.01 \% \mathrm{NaOH}$. The result of demineralization of bone material is then immersed in a $10 \% \mathrm{CaO}$ solution, where per $\mathrm{kg}$ of bone material requires 1 litre of $\mathrm{CaO}$ solution. The process of immersion of bone material is carried out for 10 days; 30 days; and 50 days. During the immersion process, stirring is done every two days. This process aims to make ossein contained in the bones to swell. After that, the bone material is washed and sprayed with water until the dirt and chalk attached to the bones are wasted.

\section{Gelatin Extraction}

The gelatin extraction process is carried out using water where each $\mathrm{kg}$ of bone needs 1 litre of soaking water with a varied extraction time of 4 hours; 5 hours; and 6 hours. Extraction was carried out in three stages with an increase in temperature that is $60^{\circ} \mathrm{C}$ (first stage); $70{ }^{\circ} \mathrm{C}$ (second stage); and $100{ }^{\circ} \mathrm{C}$ (third stage).

\section{E. Yield}

The gelatin produced was calculated based on the ratio of gelatin dry weight to the initial raw material (bovine skin material), according to Eq. (1):

$$
\text { Yield }=\frac{\text { weight of dried gelatin }(g)}{\text { weight of initial bone material }} \times 100 \%
$$

\section{F. Water Content}

Goat bone gelatin was weighed and heated for 16-18 hours at a temperature of $105 \pm 2{ }^{\circ} \mathrm{C}$. As soon as the heating is complete, the gelatin sample is weighed again. The moisture content in this analysis is the percentage of the sample weight loss.

\section{G. Ash Content}

Goat bone gelatin samples are ashed in the crucible at a temperature of $550{ }^{\circ} \mathrm{C}$ for 15 to 20 hours.

\section{H. Gel Strength}

Gel strength was gel rigidity parameter from $6.67 \%(\mathrm{~b} / \mathrm{v})$ gelatin solution measured with texture analyzer (TX2; Stevens LFRA).

\section{Viscosity}

The viscosity of the $6.67 \%(\mathrm{~b} / \mathrm{v})$ gelatin solution at a temperature of $60{ }^{\circ} \mathrm{C}$ measured using was measured using a Viscometer (Minolta CM-3500D; Minolta Co. Ltd., Osaka, Japan).

\section{J. $p H$}

the $\mathrm{pH}$ of $1.5 \%(\mathrm{~b} / \mathrm{v})$ gelatin solution was measured using a bench meter (ECION51041S; Eutech Instruments, Malaysia). at $35 \pm 1^{\circ} \mathrm{C}$.

\section{K. Colour}

Colour properties of goat bone gelatin $(6.67 \mathrm{~g} / 100 \mathrm{ml}$ dissolved at $60^{\circ} \mathrm{C}$ ) was measured using CieLab coordinates (L*, a*, b*) with colourimeter (Minolta CM-3500D; Minolta Co. Ltd., Osaka, Japan) and colour parameters were computerized in a system using Spectra Magic Software version 2.11 (Minolta Cyberchrom Inc., Osaka, Japan).

\section{RESULT AND DISCUSSION}

\section{A. Influence of curing time on the quality of gelatin products}

To determine the effect of curing time that can produce gelatin products with optimum quality, at this stage of the study the manufacture of goat bone gelatin products with curing time for 10 days, 30 days and 50 days. Figure 1 shows the type B goat gelatin products, each of which was produced with a curing time of 10 days shown in figure (a), 30 days shown in figure (b), and 50 shown in figure (c).

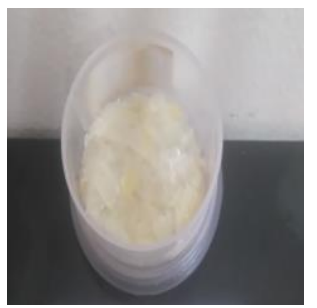

(a)

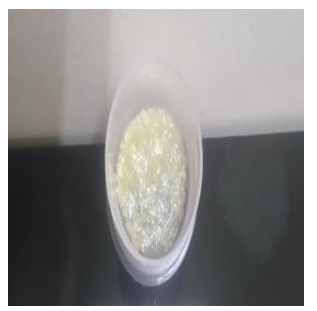

(b) 


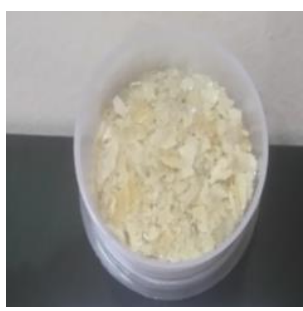

(c)

Fig. 1. Goat bone gelatin produced with curing time: (a) 10 days; (b) 30 days; and (c) 50 days

Table 1 shows the results of data analysis of the quality of the type B goat gelatin produced at each curing time. Based on these data, it can be seen that a longer curing time (50 days) that shown in figure (a) will result in a higher percentage of yield compared to a shorter curing time (10 days and 30 days) that shown in figure (b)(c). These results are in line with [11] who reported an increase in the yield of gelatin. Increased curing time will cause more time available for the curing solution to be able to decipher the structure of the triple helix on the collagen protein contained in the ossein of goat bones. The high quantity of single helix and double helix structures, each of which is produced from decomposition by acid and alkaline curing solutions will increase the potential of extractable collagen compounds, thus directly impacting the increasing percentage of gelatin yield.

Type B goat gelatin produced from a longer curing time will have higher water content. Increased curing time has provided a longer chance for the adsorption of water molecules which are solvents in the curing solution to penetrate the raw material of the goat bone used. In inverse proportion to water content, the longer curing time will result in lower ash content. Increased curing time is expected to be able to dissolve as many minerals as possible from the raw material of goat bone, to produce goat bone gelatin products which have lower ash content

In addition to increasing ash content, the increased potential for extraction of curing solutions that were not washed out during neutralization also had a direct impact on the increase in $\mathrm{pH}$ of the goat bone gelatin products obtained, bearing in mind that the curing solution used at this stage of the study was alkaline curing solution.

The results of the viscosity and strength of the gel showed decreased with increasing curing time. Deposition of curing solution in goat bone material will also optimize the process of decomposition of the triple helix structure into a single helix in the acid curing process and double helix in the alkaline curing process. The decomposition of collagen protein into monomer compounds which have a short chain will have a direct impact on the low viscosity and strength of gel gelatin goat bone products obtained. The resulting product colour does not show any significant difference as a result of the increase in curing time applied to the preparation process.
TABLE I. PHYSICO-CHEMICAL PROPERTIES OF TYPE B GOAT BONE GELATIN PRODUCED FROM CURING TIME VARIATION

\begin{tabular}{|l|c|c|c|}
\hline \multirow{2}{*}{ Properties } & \multicolumn{3}{c|}{ Curing time (days) } \\
\cline { 2 - 4 } & $\mathbf{1 0}$ & $\mathbf{3 0}$ & $\mathbf{5 0}$ \\
\hline Yield (\%) & 15.89 & 18.28 & 20.81 \\
\hline Water content (\%) & 2.0 & 3.6 & 6.3 \\
\hline Ash Content (\%) & 13.74 & 12.64 & 11.74 \\
\hline pH & 8.65 & 7.13 & 6.25 \\
\hline Viscosity (mPs) & 21.19 & 20.77 & 19.55 \\
\hline Gel Strength (Bloom) & 37.25 & 34.89 & 33.17 \\
\hline Colour (L*) & & & \\
\hline
\end{tabular}

\section{B. Influence of extraction time on the quality of gelatin} products

To determine the effect of extraction time that can produce goat bone gelatin products with optimum quality, at this stage of the research the production process of type B goat gelatin with various extraction times, including extraction time for 4 hours, 5 hours, and 6 hours. Figure 2 shows the type B goat gelatin product, each of which was produced with an extraction time of 4 hours shown in figure (a), 5 hours shown in figure (b) and 6 hours shown in figure (c).

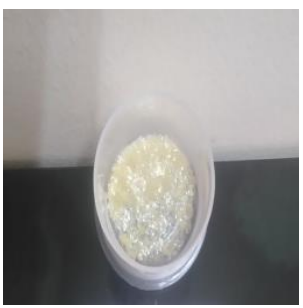

(a)

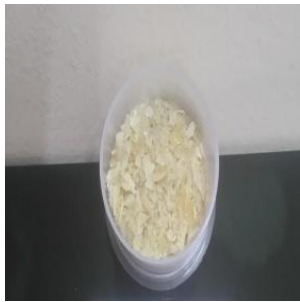

(b)

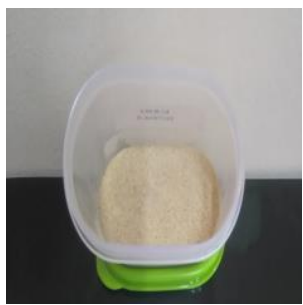

(c)

Fig. 2. Goat bone gelatin produced with extraction time: (a) 4 hour; (b) 5 hour; and (c) 6 hour 
Table II shows the results of type B goat gelatin analysis produced at each extraction time. Based on these data, it can be seen that a longer extraction time at each stage ( 6 hours) that shown in figure (a) will result in a higher percentage of yield compared to shorter extraction times (4 hours and 5 hours) that shown in figure (b)(c). The increase in yield is in line with the results of the study [12] who reported an increase in yield along with an increase in extraction time in a fish gelatin. Increased extraction time has caused more time available to maximize the number of collagen compounds that can be extracted and then converted to gelatin compounds. This is what then causes higher gelatin yields at longer extraction times.

In line with this, type B bone gelatin products produced from a longer extraction time will have higher water content. Increased extraction time will cause longer contact between gelatin compounds with water solvents thereby increasing the potential for swelling of goat bone gelatin products. This condition will inhibit the drying process of the gelatin product concerned, especially if the drying process is carried out to induce the occurrence of face hardening on the surface of the gelatin product. The event of the formation of a very dry surface or face hardening will inhibit further evaporation of molecules from inside the gelatin material and lead to a higher water content of the resulting gelatin product. Inversely proportional to the water content analysis results show that the ash content produced is lower with increasing extraction time.

However, along with these conditions some weaknesses arise in specific gelatin products obtained such as $\mathrm{pH}$ conditions, where the increase in extraction time has given a longer chance for extracting curing solution deposited in bone raw material and not washed out when neutralized using washing method. This condition will then cause the specific gelatin product obtained to have a higher $\mathrm{pH}$.

The viscosity and strength of the gel produced by goat bone gelatin decrease as the extraction time increases. This decrease is in line with what was reported by [13] on gelatin extraction increasing the extraction time from 6 hours to 12 hours causing a decrease in the strength value of gelatin gel. As explained in the previous section, the increase in curing time has led to the maximum decomposition process that occurs in collagen protein polymers which have a triple helix structure into a specific double helix in the alkaline curing process which has induced a decrease in viscosity and gel strength of the gelatin product concerned. The decomposition process becomes more intensive along with the application of the extraction process using relatively high temperatures in a long period. These conditions have resulted in a further decrease in the viscosity and gel strength of the goat bone gelatin products obtained.

The resulting colour is darker than the type $\mathrm{B}$ goat gelatin product produced from the production process with a shorter extraction time. Increased extraction time is also known to significantly influence changes in the structure of gelatin molecules. Changes in molecular structure have caused changes in specific types of orbitals in the resulting gelatin product. The high quantity of appearance of orbitals, especially non-bonding orbitals in gelatin products, will cause specific electronic transitions $n \rightarrow \pi$ and $n \rightarrow \delta$ when the gelatin product is exposed to photons and cause shifts in absorption wavelengths towards higher wavelengths [14] [15].

TABLE II. PHYSICO-CHEMICAL PROPERTIES OF TYPE B GOAT BONE GELATIN PRODUCED FROM EXTRACTION TIME VARIATION

\begin{tabular}{|l|c|c|c|}
\hline \multirow{2}{*}{ Properties } & \multicolumn{3}{c|}{ Extraction time (hours) } \\
\cline { 2 - 4 } & $\mathbf{4}$ & $\mathbf{5}$ & $\mathbf{6}$ \\
\hline Yield (\%) & 18.28 & 19.43 & 21.19 \\
\hline Water content (\%) & 3.6 & 7.4 & 8.7 \\
\hline Ash Content (\%) & 12.64 & 11.58 & 11.47 \\
\hline $\mathrm{pH}$ & 7.13 & 7.19 & 7.30 \\
\hline Viscosity (mPs) & 20.77 & 25.93 & 10.01 \\
\hline Gel Strength (Bloom) & 34.89 & 33.15 & 31.87 \\
\hline Colour (L*) & & & 84.87 \\
\hline
\end{tabular}

\section{CONCLUSION}

Goat bone gelatin (GBG) production with several different curing $(10,30$, and 50 days) and extraction times (4, 5, and 6 hours) was carried out. The results of yield evaluations and analyzes of the Physico-chemical properties of GBG produced showed that the increase in curing and extraction time had induced an increase in yield and a decrease in the overall Physico-chemical properties of GBG, including water and ash content, gel strength and brightness, at at the same time. Furthermore, concerning the gelatin quality standards set by GMIA, it can be concluded that GBG produced from curing time for 30 days and extraction time for 5 hours has the best qualifications. However, the value of GBG ash content produced in this study has not met GMIA requirements. This is predicted to be closely related to the non-neutralized alkaline post-curing procedure.

\section{ACKNOWLEDGEMENT}

Thank you to the Ministry of Research and Technology of the Republic of Indonesia Higher Education for providing financial support through the Higher Education Superior Research Program for 2019 Fiscal Year.

\section{REFERENCES}

[1] H. I. Abdullah Amqizal, H. A. Al-Kahtani, E. A. Ismail, K. Hayat and I. Jaswir, (2017). "Identification and verification of porcine DNA in commercial gelatin and gelatin containing processed foods". Food Control, 78, pp. 297-303, 2017.

[2] Z. S. Patel, S. Young, Y. Tabata, J. A. Jansen, M. E. Wong and A. G. Mikos, "Dual delivery of an angiogenic and an osteogenic growth factor for bone regeneration in a critical size defect model," Bone, 43(5), pp. 931-940, 2008.

[3] T. Ahmad, A. Ismail, S. A. Ahmad, K. A. Khalil, Y. Kumar, K. D. Adeyemi and A. Q. Sazili, "Recent advanceson the role of process variables affectinggelatin yield and characteristics with special reference to enzymatic extraction: a re-view", Food Hydrocolloids, 63, pp. 85-96, 2017. 
[4] A. Duconseille, T. Astruc, N. Quintana, F. Meersman, and V. SanteLhoutellier, "Gelatin structure and composition linked to hard capsule dissolution: A review”, Food Hydrocolloids, 43, pp. 360-376, 2015.

[5] J. Gómez-Estaca, A. López de Lacey, M. C. Gómez-Guillén, M. E. López-Caballero, and P. Montero, "Antimicrobial activity of composite edible films based on fish gelatin and chitosan incorporated with clove essential oil", Journal of Aquatic Food Product Technology, 18(1-2), pp. 46-52, 2009.

[6] F. Arioui, D. A. Saada and A. Cheriguene, "Functional properties of bovine bone gelatin and impact on physicochemical, microbiological and organoleptic quality of set yogurt”. Biotechnology, 17, pp. 1-11, 2018.

[7] J. Tkaczewska, M. Bukowski, and P. Mak, "Identification of antioxidant peptides in enzymatic hydrolysates of carp (cyprinus carpio) skin gelatin”, Molecules, 24(1), pp. 97, 2018.

[8] M. Li, F. Zhang, Z. Liu, X. Guo, Q. Wu and L. Qiao, "Controlled Release System by Active Gelatin Film Incorporated with $\beta$ Cyclodextrin-Thymol Inclusion Complexes", Food and Bioprocess Technology, 11(9), pp. 1695-1702, 2018

[9] https://lokadata.beritagar.id (accessed on 30 august 2019)

[10] R. Juliasti, A.M. Legowo and Y. B. Pramono, "Pemanfaatan limbah tulang kaki kambing sebagai sumber gelatin dengan perendaman menggunakan asam klorida", Jurnal Aplikasi Teknologi Pangan, 4 (1), pp. 5-10, 2015.

[11] H. S. Tabarestani, Y. Maghsoudlou, A. Motamedzadegan, A.R. S. Mahoonak, "Optimization of physico-chemical properties of gelatin extracted from fish skin of rainbow trout (Onchorhynchus mykiss)", Bioresource Technology, 101, pp. 6207-6214, 2010.

[12] M. Ahmad and S. Benjakul, "Characteristics of gelatin from the skin of unicorn leatherjacket (Aluterus monoceros) as influenced by acid pretreatment and extraction time", Food Hydrocolloids, 25, pp. 381388, 2011.

[13] P. Kittiphattanabawon, S. Benjakul, W. Visessanguan , F. Shahidi, "Comparative study on characteristics of gelatin from the skins of brownbanded bamboo shark and blacktip shark as affected by extraction conditions", Food Hydrocolloids, 24, pp. 164-171, 2010.

[14] A. Bahar, N. Kusumawati, M A. Anggrani, S. Muslim, "Optimization of Curing and Extraction Time on Production of Base Gelatin from Bovine Skin Material”, Advances in Social Science, Education and Humanities Research, 112, pp. 58-62, 2017.

[15] A. Bahar, Rusijono, N. Kusumawati, "Extraction and Characterization of The Base Halal Gelatin Based on Bovine Bone", Advances in Engineering Research, 171, pp. 46-49, 2018. 